\title{
Mathematical Model Describing the Influence of Geometrical Parameters of Multichannel Dies on the Limit Force of Dry Ice Extrusion Process
}

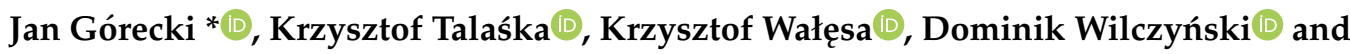 \\ Dominik Wojtkowiak \\ Faculty of Mechanical Engineering, Poznań University of Technology; 60965 Poznań, Poland; \\ krzysztof.talaska@put.poznan.pl (K.T.); krzysztof.walesa@put.poznan.pl (K.W.); \\ dominik.wilczynski@put.poznan.pl (D.W.); dominik.wojtkowiak@put.poznan.pl (D.W.) \\ * Correspondence: jan.gorecki@put.poznan.pl
}

Received: 18 June 2020; Accepted: 23 July 2020; Published: 25 July 2020

check for updates

\begin{abstract}
The article presents a formulated mathematical model that enables the determination of the required compressive force in the extrusion process of dry ice employing multichannel dies. This is the main parameter in the piston-based dry ice extrusion process. The indicated model was developed for the purpose of further improvement of the energy efficiency of this extrusion process. It allows for the determination of the value of compressive force by accounting for 12 variables related to the geometrical parameters of the die and the physical characteristics of dry ice. Furthermore, the paper also provides descriptions of the empirical study methodologies together with the results. These were carried out in order to determine the difference between the results of mathematical modeling and actual measurement results. The final part of the article presents the results of the analysis of the mathematical model's sensitivity to the change of the physical characteristics of dry ice. The formulated tool may be employed to adapt the geometric parameters of the die in order to obtain the desired compressive force value and dry ice granulation with reduced energy consumption.
\end{abstract}

Keywords: extrusion process; dry ice; multichannel die; tool design; applied mathematical model; empirical model verification

\section{Introduction}

Currently, we observe a shared interest of the international community in alleviating climate change [1,2]. Climate change is the result of, among other factors, the increase in greenhouse gas emissions, including $\mathrm{CO}_{2}$ [3,4]. Globally, the industry sectors involved in the manufacturing of ammonia compounds and power generation represent one of the major sources of $\mathrm{CO}_{2}$ emissions $[5,6]$. The indicated sources of greenhouse gas emissions are interpreted as highly focused sources, where utilization of installations for capturing $\mathrm{CO}_{2}$ is justified both by social and economic reasons [5,7]. Very often, the recovered gas becomes a side product of the process and is subject to further processing by the source entity [8]. However, the amount of recovered material usually exceeds the on-site capacity for its utilization, and therefore it is handed over to interested recipients for utilization, e.g., in the enrichment process of recovered oil or in urea system installations [5,9].

On the market, it has been observed that there are recipients interested in liquid carbon dioxide for its use in crystallization $[10,11]$. The material in this state is characterized by a temperature of $-78.5^{\circ} \mathrm{C}$ and sublimation in normal conditions $[12,13]$. Due to the indicated peculiar characteristics, it is often referred to by its common name "dry ice" [14-16]. It is used in material transportation [17,18], surface cleaning [19-24], and disinfection [16,25], among other uses. However, in the process of crystallization 
of liquid $\mathrm{CO}_{2}$, a fragmented material is obtained [26], which results in a short sublimation time and low efficiency of its use in, e.g., refrigeration processes [27]. Therefore, in order to extend the sublimation time of the material as well as to improve its use efficiency, it is compacted and delivered, e.g., in the form of pellets [28].

Pelletized dry ice is obtained through extrusion by machines employing the piston-based working system, as shown in Figure 1. As a result of the expansion of liquid $\mathrm{CO}_{2}$ in a closed, cylindrical working chamber (1), the material crystallizes. Subsequently, the motion of the compacting piston (2) compresses the fragmented dry ice. The process continues until the force applied by the piston $F_{T}$ is balanced by the resistance force $F_{E R}$ necessary to be overcome for the material to be pressed through the die channels. The resistance force value $F_{E R}$ affects the density of the product, where in order to improve the utilization efficiency of the compressed carbon dioxide, it is justified to achieve the highest possible value of the indicated material parameter [27]. The available subject literature provides formulated algebraic models describing the relation between the limit compaction force and the geometrical parameters of the convergent die channel $[29,30]$.

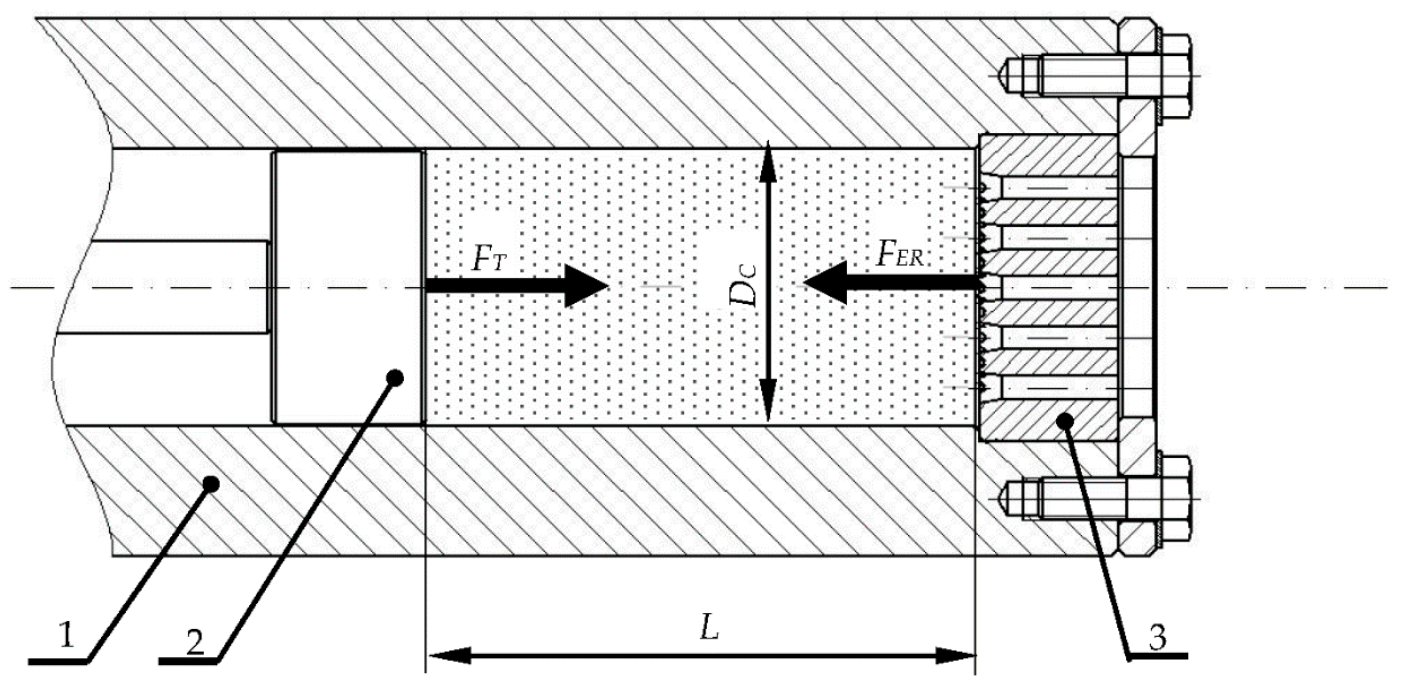

Figure 1. Extrusion system assembly utilizing the crank-piston technique: 1-working chamber, 2 - compacting piston, 3-multichannel die, $L$-agglomerated deposit height, $D_{C}$-working chamber diameter, $F_{E R}$-extrusion resistance force of die, $F_{T}$-force applied by the piston [10].

The models available in the subject literature do not relate to the extrusion of fragmented material with the utilization of multichannel dies, which are successfully employed for the extrusion of carbon dioxide. In order to fill in the gaps in the subject literature, work has been undertaken to formulate an algebraic model that makes it possible to establish the relations between the geometrical parameters of the multichannel die and the resistance force value.

\section{Theoretical Analysis of the Extrusion Process Utilizing Dies}

The analysis was carried out based on the model available in the subject literature [29]. It assumes that the compaction force necessary to carry out the extrusion process in the single convergent circular symmetrical channel results from the energy dissipation balance at the forming section $P_{D}$, which is necessary to overcome the frictional resistance $P_{\mu}$ as well as the value of linear velocity of the material at the beginning of the duct. This relationship is expressed with the following formula:

$$
F_{E R} \times v_{i n}=P_{D}+P_{u S}+P_{u C}
$$


Based on Huber's hypothesis [29], the substitute yield strength was determined as $\sqrt{3} \tau_{a}$. Hence, the dissipated power value $P_{D}$, as a function of the geometric and kinematic parameters of the process in an axial-symmetrical channel can be described with the following Equation:

$$
P_{D}=\sqrt{15} \times \tau_{a} \times v_{\text {in }} \times \frac{D_{\text {in }}^{2}}{4} \times \ln \frac{D_{\text {in }}}{D_{\text {out }}}
$$

Based on the product displacement value, an algebraic formula was established to describe the variance in energy dissipation due to friction in a symmetrically convergent forming channel $P_{\mu \mathrm{S}}$ :

$$
P_{u s}=\int_{S_{s}} u_{T} \times \tau_{a} \times w_{k} d S_{s}
$$

where $S_{S}$ is the surface area of the side of the convergent section. Its value can be described with the following formula:

$$
S_{s}=\int_{S_{s}} 2 \pi \times R(z) d S_{s}
$$

After integration and transformation of the above equations (refer to Equations (3) and (4)) we arrive at the following equation:

$$
P_{u S}=\mu_{T} \times \tau_{a} \times \frac{v_{\text {in }} \times D_{\text {in }}^{2}}{\cos \alpha \times D_{\text {out }}^{2}} \times \frac{2 \pi}{\cos \alpha}\left(\frac{D_{\text {in }}}{2} \times b-\frac{b^{2}}{2} \times \tan \alpha\right)
$$

Subsequently, frictional power in the cylindrical section of the forming channel was determined similarly, using the following Equation:

$$
P_{\mu C}=\int_{S_{C}} \mu_{T} \times \tau_{a} \times v_{\text {in }} d S_{C}
$$

where $S_{C}$ is the surface area of the side of the cylindrical section, which can be described with the following Equation:

$$
S_{C}=\int_{\theta=0}^{2 \pi} \int_{z=0}^{a} \frac{D_{\text {out }}}{2} d z d \theta=\int_{\theta=0}^{2 \pi} \int_{z=0}^{a} \frac{D_{\text {in }}}{2}-b \times \tan \alpha d z d \theta .
$$

After integration and transformation of Equations (6) and (7), we arrive at the following equation:

$$
P_{\mu C}=\mu_{T} \times \tau_{a} \times v_{\text {in }} \times \frac{D_{\text {out }}^{2}}{4 \times D_{\text {in }}} \times a
$$

After making transformations to the model (Equation (1)), we arrive at the relation binding the indicated force value to the geometrical parameters of the single channel die, as well as the physical characteristics of the compacted material (such as the shear stress of the pellet $\tau_{a}$ and the static friction coefficient $\mu_{T}$ ). The relationship is expressed with the following formula:

$$
F_{E R}=\tau_{a} \frac{D_{\text {in }}^{2}}{4}\left(\sqrt{15} \times \ln \frac{D_{\text {in }}}{D_{\text {out }}}+2 \pi \times \mu_{T}\left(\frac{4}{\cos ^{2} \alpha \times D_{\text {out }}{ }^{2}}\left(\frac{D_{\text {in }}}{2} \times b-\frac{b^{2}}{2} \tan \alpha\right)+\frac{2 \alpha}{D_{\text {out }}}\right)\right)
$$

The theoretical analysis of the extrusion process utilizing dies with $\mathrm{n}$ symmetrical circular forming channels, as shown in Figure 2, calls for developing the model provided in the subject literature to include the following constituents of the balance: energy required to separate the extruded material $P_{T}[27,31]$, energy dissipated during deformation of the extruded material $P_{D P P}$ on the surface perpendicular to axis $z S_{P P}[10]$, and energy dissipated as a result of friction by the material 
as the extruded material moves inside the working chamber $P_{\mu \mathrm{C}}$. The developed relationship can be expressed as:

$$
F_{E R} \times v_{i n}=n \times\left(P_{D}+P_{\mu}\right)+P_{T}+P_{D P P}+P_{\mu C}
$$

Analogous to the earlier model, after transforming the formula, we arrive at the relationship binding the value $F_{E R}$ to the geometrical parameters of the channel (where additionally the following variables were accounted for: the number of channels $n$, length and diameter of the working chamber $D_{C}$, side length of the hexagon on which the orifices $e$ were distributed, and number of channels arranged on a hexagon $n_{G}$ ), as well as the material and the process, i.e., the length of the extruded material before it is introduced into the die channels $l_{T}$. The resulting relationship is expressed as

$$
\begin{aligned}
F_{E R}= & \tau_{a}\left(n \frac{D_{\text {in }}{ }^{2}}{4}\left(\sqrt{15} \times \ln \frac{D_{\text {in }}}{D_{\text {out }}}+2 \pi \mu_{T}\left(\frac{4}{\cos ^{2} \alpha D_{\text {out }}{ }^{2}}\left(\frac{D_{\text {in }}}{2} b-\frac{b^{2}}{2} \tan \alpha\right)+\frac{2 \alpha}{D_{\text {out }}}\right)\right)\right. \\
& \left.+l_{T} n D_{\text {in }}+\mu_{T}\left(\pi \frac{D_{C}}{4}-\frac{3 e^{2} \sqrt{3}}{2}+\frac{\pi n_{G} D_{\text {in }}{ }^{2}}{8}\right)+\pi \mu_{T} D_{C} l_{T}\right)
\end{aligned}
$$

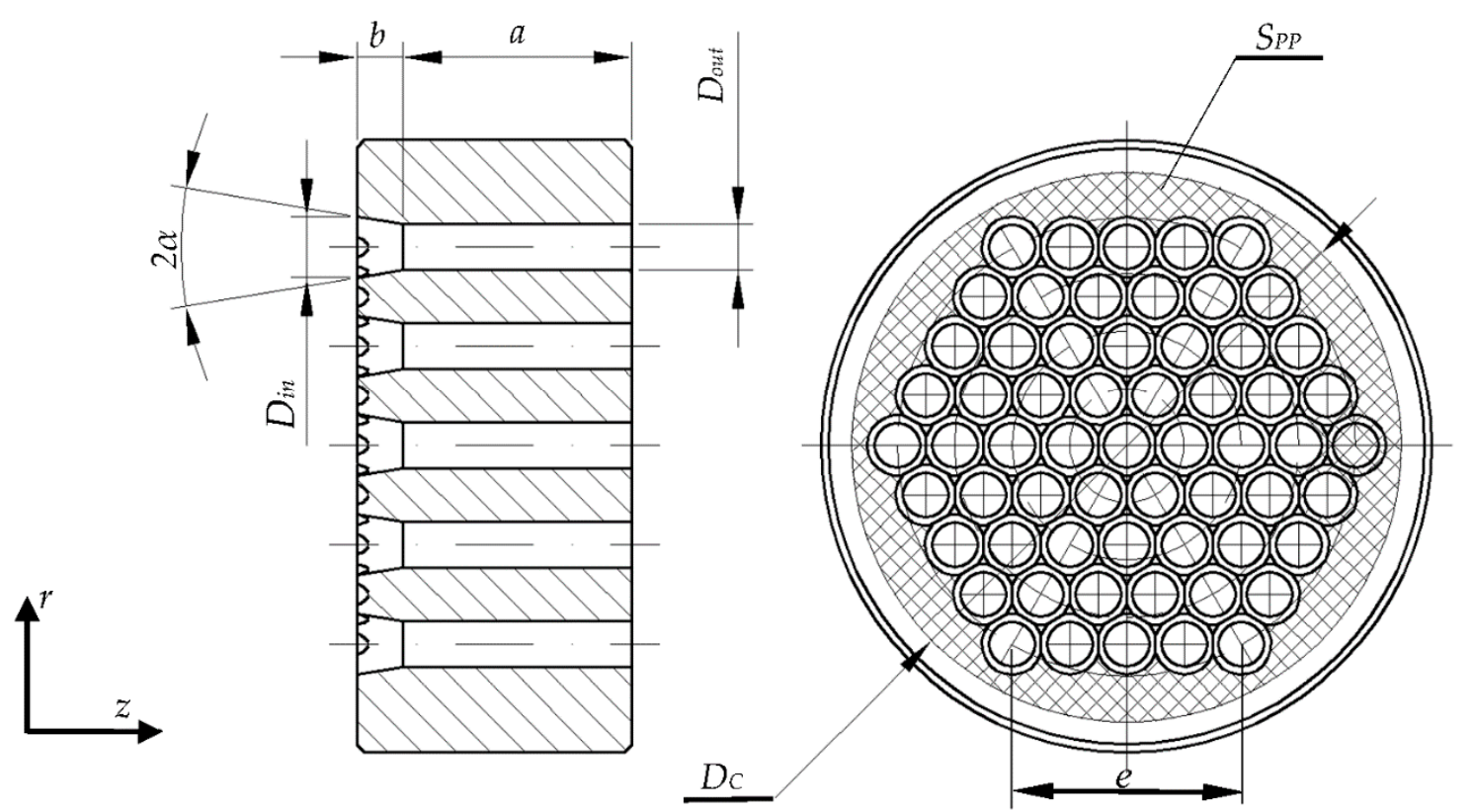

Figure 2. EMultiorifice die: $\alpha$-convergence angle of the conical section, $a$-length of the conical section, $b$-length of the cylindrical section, $D_{i n}$-input diameter of the conical section, $D_{\text {out }}$-output diameter of the cylindrical section, $e$-side length of the hexagon on which the channels are distributed, $S_{P P}$-surfaces perpendicular to the direction of the piston displacement vector, $D_{C}-$ a diameter of the compaction chamber.

\section{Empirical Verification of the Developed Model}

The formulated model was verified by carrying out the program of empirical data. The study was based on the methodology provided in the subject literature [32].

Experiments carried out for the purpose of the study used four dies with parameters as provided in Table 1.

Table 1. Geometrical parameters of the dies.

\begin{tabular}{cccccccccc}
\hline Name of Die & $\boldsymbol{n}$ & $\boldsymbol{D}_{\text {out }}(\mathbf{m m})$ & $\boldsymbol{D}_{\text {in }}(\mathbf{m m})$ & $\boldsymbol{\alpha}\left({ }^{\circ} \mathbf{C}\right)$ & $\boldsymbol{a}(\mathbf{m m})$ & $\boldsymbol{b}(\mathbf{m m})$ & $\boldsymbol{D}_{\boldsymbol{C}}(\mathbf{m m})$ & $\boldsymbol{e}(\mathbf{m m})$ & $n_{G}$ \\
\hline MCD-0 & 61 & 3 & 4.06 & & 15 & 3 & & 15 & 24 \\
MCD-1 & 37 & 3 & 5.12 & 10 & 12 & 6 & 36 & 15 & 18 \\
MCD-2 & 37 & 4.5 & 5.56 & & 15 & 3 & & 15 & 18 \\
MCD-3 & 37 & 4.5 & 5.56 & 22 & 3 & & 15 & 18 \\
\hline
\end{tabular}


Analogous to the methodology provided in the subject literature, the study employed the MTS Insight testing machine (MTS System Corporation, Eden Prairie, MN, USA) equipped with a $50 \mathrm{kN}$ tensometric sensor. During the examination, the force value provided at the compressing piston $F_{P}$ and crossbeam displacement $x$ was measured and registered with a constant frequency of $10 \mathrm{~Hz}$. The study was performed at a constant velocity value equal to $9 \mathrm{~mm} / \mathrm{s}$. The measurements were repeated 10 times for every one of four dies described above.

The study employed the testing station that was designed and built as shown in Figure 3.

During testing, the compaction chamber (1) was filled with fragmented dry ice. The assembled unit was placed between the testing machine grips (7). After taring the value of the measurement signal, the movement of the piston (3) was forced, which was accompanied by compaction of fragmented dry ice until the values of available force at the piston $F_{P}$ and resistance force $F_{E R}$ were equal. Then, the extruded material was moved further through the forming die channels (4).

a)

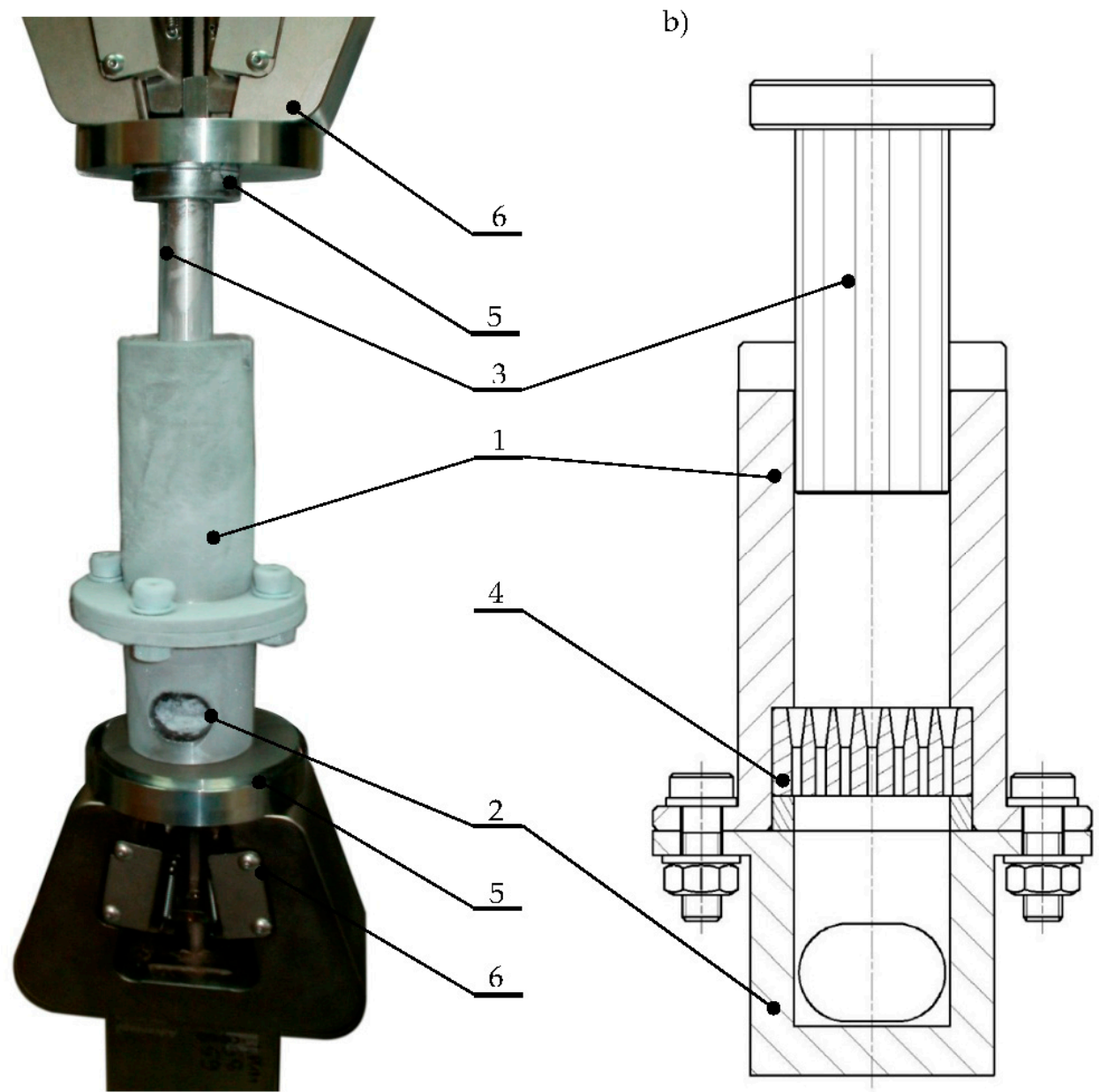

Figure 3. Measuring unit: (a) MTS machine grips with measuring head and alignment system; (b) cross-section of the measuring head: 1-compaction chamber, 2-head base, 3-piston, 4-multichannel forming die, 5-alignment jig, 6-jaws of testing machine [27].

The results of the examination were used to determine the maximum force value available at the piston $F_{T}$ and its corresponding compacting piston displacement value for each of the four tested dies.

The point at which the force applied at the piston $F_{T}$ is at its maximum value is related with overcoming the resistances associated with the forming of the compacted material in the die. This method of determination of the maximum value of force at piston $F_{T}$ is tantamount to determining the empirical value of the resistance force $F_{E R}$ at the same point in the examined die. The information on the position of this point was furthermore used to determine the value of the length 
of the cutting edge along the axis of the compaction chamber $l_{T}$, which was utilized further in this paper for calculating the value of resistance force $F_{E R}$ with utilization of the analytical model.

As an estimator of the sought limit axial force value, the average value $F_{E R}{ }^{a v r}$ was assumed. For every value, measurement inaccuracy was determined, which was equal to the standard deviation of the results. The estimator values $F_{E R}$ avr and $l_{T}$ are provided in Table 2.

Table 2. Estimated values of limit axial force.

\begin{tabular}{ccccc}
\hline Name of the Die & MCD-0 & MCD-1 & MCD-2 & MCD-3 \\
\hline$F_{E R^{\text {avr }}}(\mathrm{kN})$ & $23.1 \pm 2.3$ & $16.6 \pm 2.4$ & $18.45 \pm 0.69$ & $19.67 \pm 0.82$ \\
$l_{T}(\mathrm{~mm})$ & 21.0 & 17 & 20.5 & 21 \\
\hline
\end{tabular}

Based on the geometrical properties provided in Table 1 above, the extrusion resistance force $F_{E R}{ }^{A}$ was calculated for the examined dies. The results of the analysis are provided in Table 3 . At the determination of the value of the relative error of the model $\delta$, standard deviation $\sigma$ was included in the consideration in relation to the value $F_{E R}$ avr. The final relationship was expressed with the following Equation:

$$
\delta=\frac{F_{E R}^{a v r} \pm \sigma-F_{E R}{ }^{A}}{F_{E R^{a v r}} \pm \sigma} \times 100 \%
$$

The determined error values together with the results of the analysis and examination are presented in the table below.

Table 3. Analysis results for $F_{E R}$ force value of forming dies.

\begin{tabular}{ccccc}
\hline Name of the Die & MCD-0 & MCD-1 & MCD-2 & MCD-3 \\
\hline$F_{E R}{ }^{A}(\mathrm{kN})$ & 22.12 & 18.70 & 19.76 & 20.38 \\
$F_{E R}$ avr $(\mathrm{kN})$ & $23.1 \pm 2.3$ & $16.6 \pm 2.4$ & $18.45 \pm 0.69$ & $19.67 \pm 0.82$ \\
$\delta(\%)$ & $-6.3-12.9$ & $-31.69-1.58$ & $-11.26-3.24$ & $-8.12-0.54$ \\
\hline
\end{tabular}

The results obtained from the calculations for the MCD-0, MCD-2, and MCD-3 dies are within the dispersion range of the study results.

Based on the results of the model error analysis and the performed examination, it was determined that the established mathematical model makes it possible to derive the approximate force value $F_{E R}$. Therefore, the results obtained from the analytically formulated model may be used for the purpose of designing machines used for the compaction of crystallized carbon dioxide with the utilization of multichannel dies.

\section{Susceptibility of the Algebraic Model to Variance in Physical Characteristics of the Extruded Dry Ice}

This section describes the next step of this work, where the developed and verified algebraic model was used for the analysis of its susceptibility to variance in the physical parameters of the material. The geometrical parameters of the model describing the multichannel dies employed earlier remained unchanged. The values subject to change were pellet shear strength $\tau_{a}$, in the range $1-2 \mathrm{MPa}$, and frictional coefficient $\mu$, in the range 0.001-0.01. The results of the computation are displayed in Figures 4-7.

The developed characteristics demonstrate a linear influence of both parameters on the $F_{E R}$ value, which is substantiated by the calculated correlation coefficient value equal to 1 . In order to compare the model susceptibility to variance in both parameters under analysis, the model gradient value was determined in the examined range. The results are provided in Tables 4 and 5. 


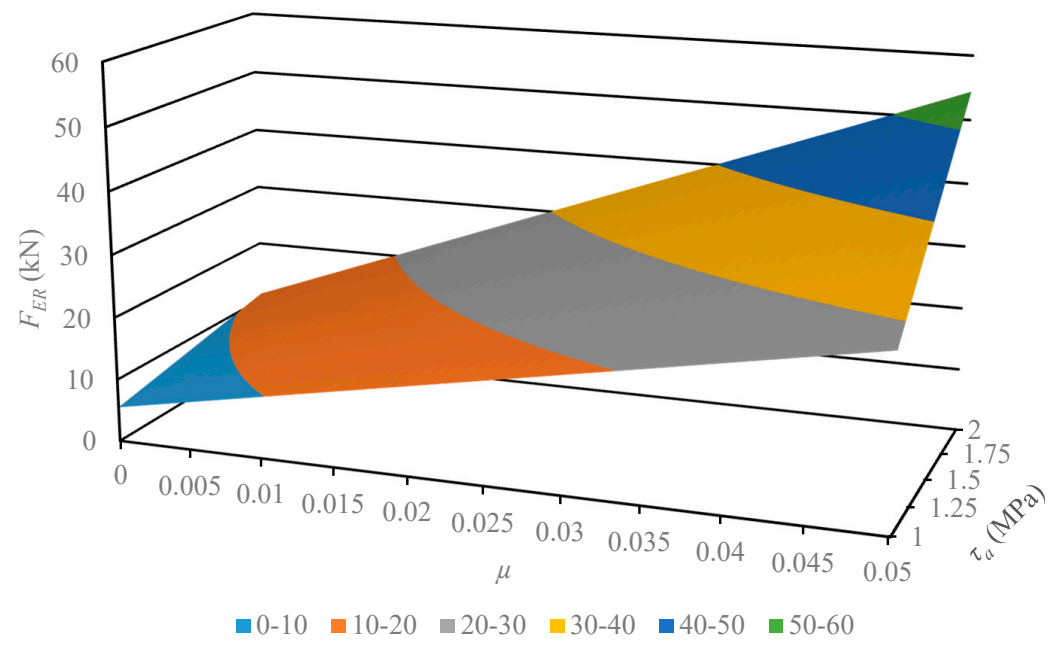

Figure 4. Characteristics of the limit value extrusion force $F_{E R}$ of dry ice in a function of material parameters (shear strength $\tau_{a}$ and friction coefficient $\mu$ ), in the case of using the MCD- 0 multichannel die.

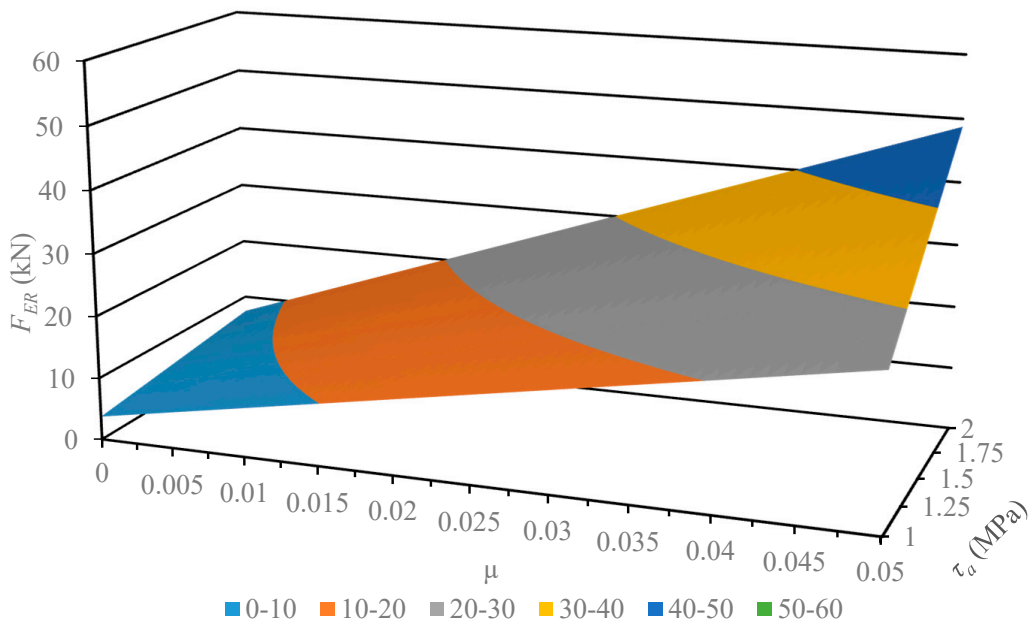

Figure 5. Characteristics of the limit value extrusion force $F_{E R}$ of dry ice in a function of material parameters (shear strength $\tau_{a}$ and friction coefficient $\mu$ ), in the case of using the MCD-1 multichannel die.

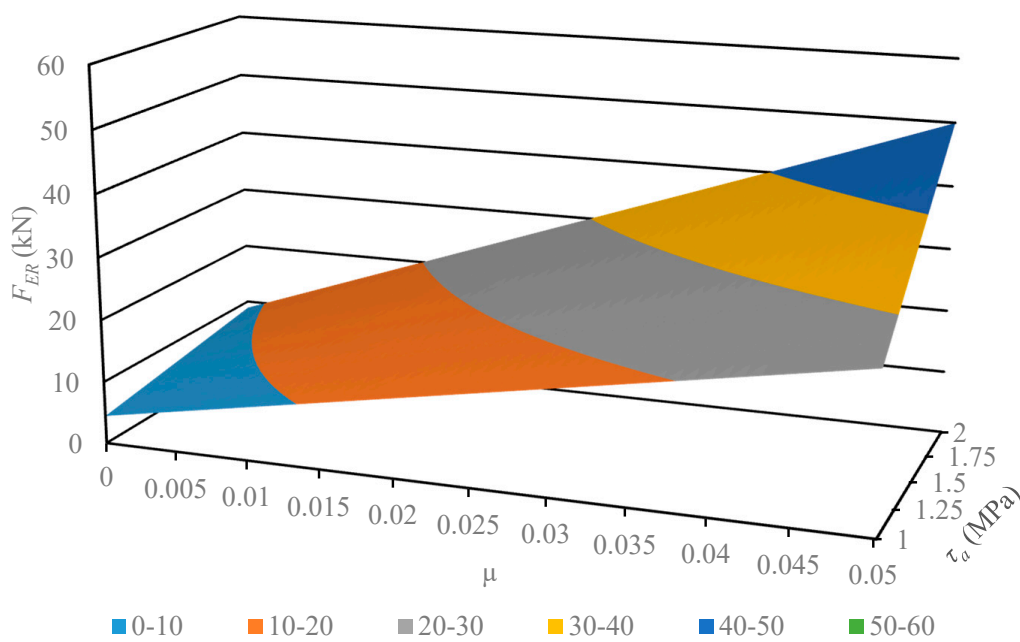

Figure 6. Characteristics of the limit value extrusion force $F_{E R}$ of dry ice in a function of material parameters (shear strength $\tau_{a}$ and friction coefficient $\mu$ ), in the case of using the MCD-2 multichannel die. 


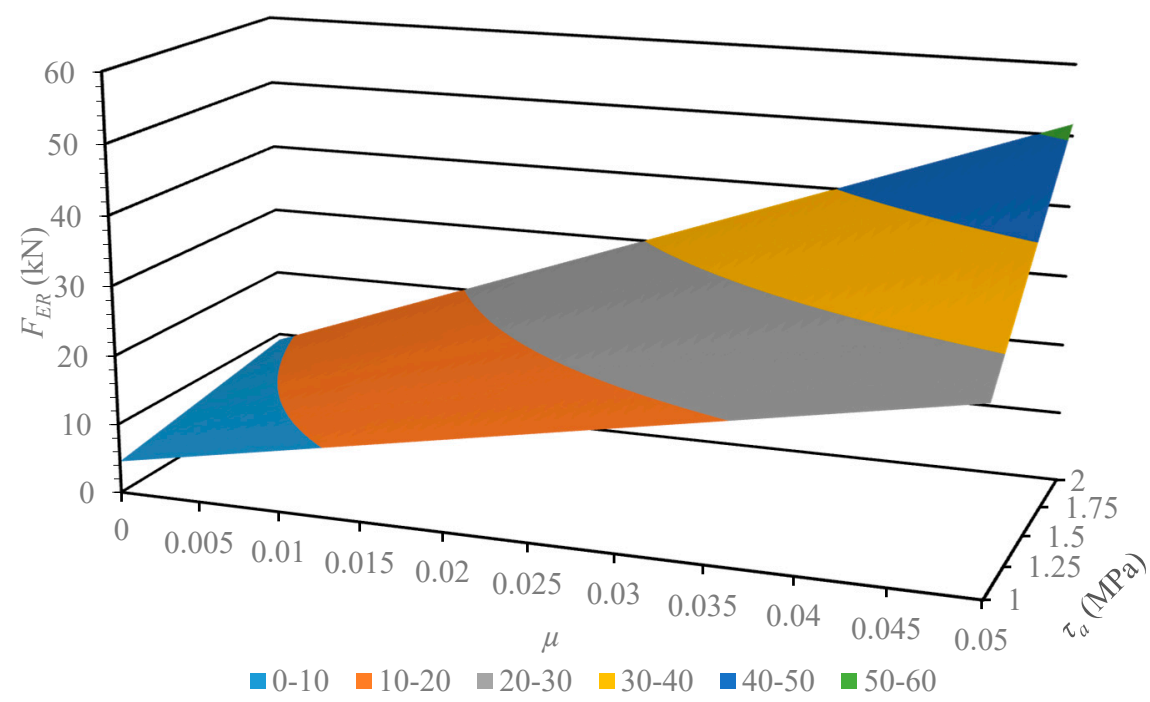

Figure 7. Characteristics of the limit value extrusion force $F_{E R}$ of dry ice in a function of material parameters (shear strength $\tau_{a}$ and friction coefficient $\mu$ ), in the case of using the MCD-3 multichannel die.

Table 4. The characteristic gradient value describing the variance in limit force as a function of $\tau_{a}$, for different values of $\mu$.

\begin{tabular}{cccccc}
\hline Gradient of Function & $\boldsymbol{\mu}=\mathbf{0 . 0 0 1}$ & $\boldsymbol{\mu}=\mathbf{0 . 0 0 2}$ & $\boldsymbol{\mu = \mathbf { 0 . 0 0 5 }}$ & $\boldsymbol{\mu = \mathbf { 0 . 0 0 7 5 }}$ & $\boldsymbol{\mu}=\mathbf{0 . 0 1}$ \\
\hline$\nabla f^{M C D-0}\left(\tau_{a}\right)=\frac{d f^{M C D-0}}{d \tau_{\tau}}(\mathrm{kN})$ & 9.8 & 8.8 & 7.7 & 6.4 & 5.9 \\
$\nabla f^{M C D-1}\left(\tau_{a}\right)=\frac{d f^{M C D-1}}{d \tau_{a}}(\mathrm{kN})$ & 7 & 6.8 & 5.8 & 4.5 & 4.1 \\
$\nabla f^{M C D-2}\left(\tau_{a}\right)=\frac{d f^{M C D-2}}{d \tau_{2}}(\mathrm{kN})$ & 8.6 & 7.5 & 6.5 & 5.2 & 4.9 \\
$\nabla f^{M C D-3}\left(\tau_{a}\right)=\frac{d f^{M C D-3}}{d \tau_{a}}(\mathrm{kN})$ & 8.8 & 7.7 & 6.7 & 5.4 & 5.0 \\
\hline
\end{tabular}

Table 5. The characteristic gradient value describing the variance in limit force as a function of $\mu$, for different values of $\tau_{a}$.

\begin{tabular}{cccccc}
\hline Gradient of Function & $\begin{array}{c}\tau_{a}=\mathbf{1} \\
\mathbf{( M P a}\end{array}$ & $\begin{array}{c}\tau_{a}=\mathbf{1 . 1} \\
(\mathbf{M P a})\end{array}$ & $\begin{array}{c}\boldsymbol{\tau}_{a}=\mathbf{1 . 5} \\
\mathbf{( M P a})\end{array}$ & $\begin{array}{c}\tau_{a}=\mathbf{1 . 7 5} \\
(\mathbf{M P a})\end{array}$ & $\begin{array}{c}\boldsymbol{\tau}_{\boldsymbol{a}}=\mathbf{2} \\
(\mathbf{M P a})\end{array}$ \\
\hline$\nabla f^{M C D-0}(\mu)=\frac{d f^{M C D-0}}{d \mu}(\mathrm{kN})$ & 868.8 & 760.2 & 651.6 & 477.8 & 434.4 \\
$\nabla f^{M C D-1}(\mu)=\frac{d f^{M C D-1}}{d \mu}(\mathrm{kN})$ & 826.8 & 723.5 & 620.1 & 454.8 & 413.4 \\
$\nabla f^{M C D-2}(\mu)=\frac{d f^{M C D-2}}{d \mu}(\mathrm{kN})$ & 821.4 & 718.6 & 616.1 & 451.8 & 410.7 \\
$\nabla f^{M C D-3}(\mu)=\frac{d f^{M C D-3}}{d \mu}(\mathrm{kN})$ & 851.5 & 745.0 & 638.6 & 768.3 & 425.7 \\
\hline
\end{tabular}

The results of the model susceptibility analysis provided in the tables indicate that it is approximately 100 times more susceptible to variance in $\mu$ value than $\tau_{a}$ value. It should be noted that is it easier to modify the value of the friction coefficient, which is related to the roughness of channel surfaces. The value of shear stress is related to the density of compacted material, where it is known as a quality factor of the product. Therefore, researchers in the future should focus on the influence of channel surface roughness and geometrical parameters on the value of extrusion force $F_{E R}$. This will be necessary to reduce the value of limit extrusion stress to an effective level, which equals $14 \mathrm{MPa}$ [27].

\section{Summary}

The formulated algebraic model was verified empirically. This makes it possible to estimate the value of limit force necessary to perform the extrusion process of dry ice utilizing multichannel dies with a known error. 
Models that are known in the literature allow calculation of the extrusion force when single-channel dies are used in the machine. The authors of this paper could not find models that allow calculation of the extrusion limit force in cases when multichannel dies are used. Where multichannel dies are a standard solution in the process of extrusion, dry ice pellets are $3 \mathrm{~mm}$ in diameter or less.

The preliminary analysis of model susceptibility to the variability of physical parameter values of compacted crystallized carbon dioxide indicates that the force $F_{E R}$ value is more materially influenced by the value of the frictional coefficient $\mu$ than its shear strength $\tau_{a}$. This justifies the significant difference between the calculated and actual values. The authors did not measure the porosity of the sides of forming channels in the dies used in the experiment during empirical testing. However, this does not reduce the utility of the developed model.

The formulated model could be used to calculate the extrusion limit force of the designed die. It could be also used in optimization research whose main goal will be reducing the value of the limit extrusion stress to the effective value of $14 \mathrm{MPa}$ [27]. In the available literature focused on the optimization of the tool shape, the optimization algorithms are well described [33-35]. It is likely that in the next stage of research they will be implemented in studies concerning the optimization of the die channel shape.

The formulated model may be developed further to enable the determination of the value of limit strength of the process utilizing multichannel dies with a shape other than conical or cylindrical.

Author Contributions: Conceptualization, J.G. and K.T.; methodology, J.G.; formal analysis, J.G. and D.W. (Dominik Wojtkowiak); investigation, D.W. (Dominik Wilczyński) and J.G.; data curation, K.W.; writing-original draft preparation, J.G.; supervision, J.G. All authors have read and agreed to the published version of the manuscript.

Funding: This research received no external funding.

Conflicts of Interest: The authors declare no conflict of interest.

\section{References}

1. Chikukwa, A.; Enaasen, N.; Kvamsdal, H.M.; Hillestad, M. Dynamic modeling of post-combustion $\mathrm{CO}_{2}$ capture using amines-A review. Energy Procedia 2012, 23, 82-91. [CrossRef]

2. IPCC. Global Warming of $1.5^{\circ} \mathrm{C}$; Masson-Delmotte, V., Zhai, P., Pörtner, H.O., Roberts, D., Skea, J., Shukla, P.R., Pirani, A., Moufouma-Okia, W., Péan, C., Pidcock, R., et al., Eds.; An IPCC Special Report on the Impacts of Global Warming of $1.5^{\circ} \mathrm{C}$ above Pre-Industrial Levels and Related Global Greenhouse Gas Emission Pathways, in the Context of Strengthening the Global Response to the Threat of Climate Change, Sustainable Development, and Efforts to Eradicate Poverty; IPCC: Geneva, Switzerland, 2018.

3. Mazzoldi, A.; Hill, T.; Colls, J. $\mathrm{CO}_{2}$ transportation for carbon capture and storage: Sublimation of carbon dioxide from a dry ice bank. Int. J. Greenh. Gas Control 2008, 2, 210-218. [CrossRef]

4. Putman, W.; Ott, L.; Darmenov, A.; DaSilva, A. A global perspective of atmospheric carbon dioxide concentrations. Parallel Comput. 2016, 55, 2-8. [CrossRef]

5. Metz, B.; Davidson, O.; De Coninck, H.; Loos, M.; Meyer, L. IPCC Special Report on Carbon Dioxide Capture and Storage; Cambridge University Press: Cambridge, UK, 2005; Volume 4.

6. Spur, G.; Uhlmann, E.; Elbing, F. Dry-ice blasting for cleaning: Process, optimization and application. Wear 1999, 233, 402-411. [CrossRef]

7. VanSant, J. Carbon Dioxide Emission and Merchant Market in the European Union; Springer Science and Business Media: Berlin, Germany, 2003; pp. 3-50.

8. Leites, I.; Sama, D.; Lior, N. The theory and practice of energy saving in the chemical industry: Some methods for reducing thermodynamic irreversibility in chemical technology processes. Energy 2003, 28, 55-97. [CrossRef]

9. Beecy, D.J.; Kuuskraa, V.A. Basic strategies for Linking $\mathrm{CO}_{2}$ enhanced oil recovery and storage of $\mathrm{CO}_{2}$ emissions. In Proceedings of the 7th International Conference on Greenhouse Gas Control Technologies (GHGT-7), Vancouver, BC, Canada, 5 September 2004; Volume 1, pp. 351-360.

10. Górecki, J.; Malujda, I.; Talaśka, K.; Wojtkowiak, D. Dry ice compaction in piston extrusion process. Acta Mech. Autom. 2017, 11, 313-316. [CrossRef] 
11. Uhlmann, E.; Kretzschmar, M.; Elbing, F.; Mihotovic, V. Deburring with $\mathrm{CO}_{2}$ now blasting. In Analysis, Control and Removal; Springer: Berlin, Germany, 2010.

12. Górecki, J.; Malujda, I.; Talaśka, K.; Wilczyński, D.; Wojtkowiak, D. Influence of geometrical parameters of convergent sleeve on the value of limit stress. MATEC Web Conf. 2018, 157, 05006. [CrossRef]

13. Liu, Y.; Calvert, G.; Hare, C.; Ghadiri, M.; Matusaka, S. Size measurement of dry ice particles produced form liquid carbon dioxide. J. Aerosol Sci. 2012, 48, 1-9. [CrossRef]

14. Dong, S.J.; Song, B.; Hansz, B.; Liao, H.L.; Coddet, C. Modelling of dry ice blasting and its application in thermal spray. Mater. Res. Innov. 2012, 16, 61-66. [CrossRef]

15. Gorecki, J.; Malujda, I.; Talaśka, K.; Kukla, M.; Tarkowski, P. Static compression tests of concentrated crystallized carbon dioxide. Appl. Mech. Mater. 2015, 816, 490-495. [CrossRef]

16. Witte, A.K.; Bobal, M.; David, R.; Blättler, B.; Schoder, D.; Rossmanith, P. Investigation of the potential of dry ice blasting for cleaning and disinfection in the food production environment. LWT 2017, 75, 735-741. [CrossRef]

17. Chen, L.; Zhang, X. A review study of solid-gas sublimation flow refrigeration: Form basic mechanism to applications. Int. J. Refrig. 2014, 40, 61-83. [CrossRef]

18. Yamaguchi, H.; Niu, X.; Sekimoto, K.; Neksa, P. Investigation of dry ice blockage in an ultra-low temperature cascade refrigeration system using $\mathrm{CO}_{2}$ as a working fluid. Int. J. Refrig. 2011, 34, 466-475. [CrossRef]

19. Dzido, A.; Krawczyk, P.; Kurkus-Gruszecka, M. Numerical analysis of dry ice blasting convergent-divergent supersonic nozzle. Energies 2019, 12, 4787. [CrossRef]

20. Tang, S.; Zhou, P.; Wang, X.; Yu, Y.; Li, H. Design and experiment of dry-ice cleaning mechanical arm for insulators in substation. Appl. Sci. 2020, 10, 2461. [CrossRef]

21. Pozo-Antonio, J.S.; López, L.; Dionisio, A.; Rivas, T. A study on the suitability of mechanical soft-abrasive blasting methods to extract graffiti paints on ornamental stones. Coatings 2018, 8, 335. [CrossRef]

22. Li, M.-Z.; Liu, W.-W.; Qing, X.-C.; Yu, Y.; Liu, L.-H.; Tang, Z.-J.; Wang, H.-J.; Dong, Y.-Z.; Zhang, H.-C.; Wei-Wei, L. Feasibility study of a new approach to removal of paint coatings in remanufacturing. J. Mater. Process. Technol. 2016, 234, 102-112. [CrossRef]

23. Liu, Y.-H.; Hirama, D.; Matsusaka, S. Particle removal process during application of impinging dry ice jet. Powder Technol. 2012, 217, 607-613. [CrossRef]

24. Máša, V.; Kuba, P. Efficient use of compressed air for dry ice blasting. J. Clean. Prod. 2016, 111, 76-84. [CrossRef]

25. Otto, C.; Zahn, S.; Rost, F.; Zahn, P.; Jaros, D.; Rohm, H. Physical methods for cleaning and disinfection of surfaces. Food Eng. Rev. 2011, 3, 171-188. [CrossRef]

26. Liu, Y.-H.; Maruyama, H.; Matsusaka, S. Agglomeration process of dry ice particles produced by expanding liquid carbon dioxide. Adv. Powder Technol. 2010, 21, 652-657. [CrossRef]

27. Górecki, J.; Malujda, I.; Talaśka, K.; Tarkowski, P.; Kukla, M. Influence of the value of limit densification stress on the quality of the pellets during the agglomeration process of $\mathrm{CO}_{2}$. Procedia Eng. 2016, 136, $269-274$. [CrossRef]

28. Talaśka, K. Study of Research and Modelling of Compaction Processes of Powder and Shredded Materials; Poznan University of Technology: Poznań, Poland, 2018.

29. Malujda, I. Modeling of Limit Stress Fields and Temperature in Plasticizing and Compaction Processes Oriented to the Needs of Machine Design; Poznan University of Technology: Poznań, Poland, 2012. (In Polish)

30. Piwnik, J. Theory of the Experiment in the Analysis of Extrusion Processes; Bialystock University of Technology: Białystok, Poland, 2010. (In Polish)

31. Górecki, J.; Malujda, I.; Talaśka, K. Investigation of internal friction of agglomerated dry ice. Procedia Eng. 2016, 136, 275-279. [CrossRef]

32. Górecki, J.; Malujda, I.; Talaśka, K.; Kukla, M.; Tarkowski, P. Influence of the compression length on the ultimate stress in the process of mechanical agglomeration of dry ice. Procedia Eng. 2017, 177, 363-368. [CrossRef]

33. Ning, J.; Nguyen, V.; Liang, S.Y. Analytical modeling of machining forces of ultra-fine-grained titanium. Int. J. Adv. Manuf. Technol. 2018, 101, 627-636. [CrossRef] 
34. Ning, J.; Nguyen, V.; Huang, Y.; Hartwig, K.T.; Liang, S.Y. Inverse determination of Johnson-Cook model constants of ultra-fine-grained titanium based on chip formation model and iterative gradient search. Int. J. Adv. Manuf. Technol. 2018, 99, 1131-1140. [CrossRef]

35. Zuo, K.-T.; Chen, L.-P.; Zhang, N.; Yang, J. Manufacturing- and machining-based topology optimization. Int. J. Adv. Manuf. Technol. 2005, 27, 531-536. [CrossRef]

(C) 2020 by the authors. Licensee MDPI, Basel, Switzerland. This article is an open access article distributed under the terms and conditions of the Creative Commons Attribution (CC BY) license (http://creativecommons.org/licenses/by/4.0/). 